\title{
Research on the Development Model of Equilibrium Function of Chinese Undergraduate Universities
}

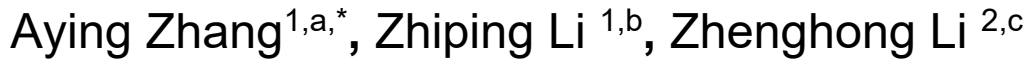 \\ ${ }^{1}$ Harbin University, 150086 Harbin, China \\ ${ }^{2}$ Harbin Institute of Technology, 150001 Harbin, China \\ a,`zaying@sina.com, blizp2008@126.com, c273662999@qq.com
}

Keywords: Development model, Equilibrium function, Undergraduate, Universities.

\begin{abstract}
According to the school-running logic of undergraduate universities, there are five juxtaposition elements, such as students, teachers, conditions, management and culture. By using the regression analysis method of modern statistics, this paper quantitatively analyzes the influence of 5 parallel elements on the level of running a university. The conclusion is that the level of teachers is the main factor affecting the school running level, and the interaction between the student factors and the conditional factors has a positive influence on the school running level. The interaction between management factors and cultural factors has a positive correlation with the level of school running. Furthermore, this paper puts forward the coordinated development model of the Undergraduate University of the undergraduate university, which includes the various elements of the undergraduate university, while the quantity is developed, the quality of each element is in conformity with the requirements and coordinated development with each other.
\end{abstract}

\section{Introduction}

The research indicates that according to the role and status of elements in the system, elements are divided into main elements, basic elements, general elements and related elements. The main factor is the factor that represents the function of the system. This element is often the main carrier of the function of the system. That is, the role of this element in the system and the function of the system is in the same nature and the same direction.

Basic elements are the basic elements to play the role of the main elements of support. The basic status of this element is relative to the main elements, and the basis for the role of the main elements. Generic elements refer to the same elements of similar systems. The related factors refer to the elements related to the functions of the main elements, which are generally other elements besides the main elements, basic elements and common elements.

\section{Technical structure model}

The four element diagram is shown as shown in Figure 1.

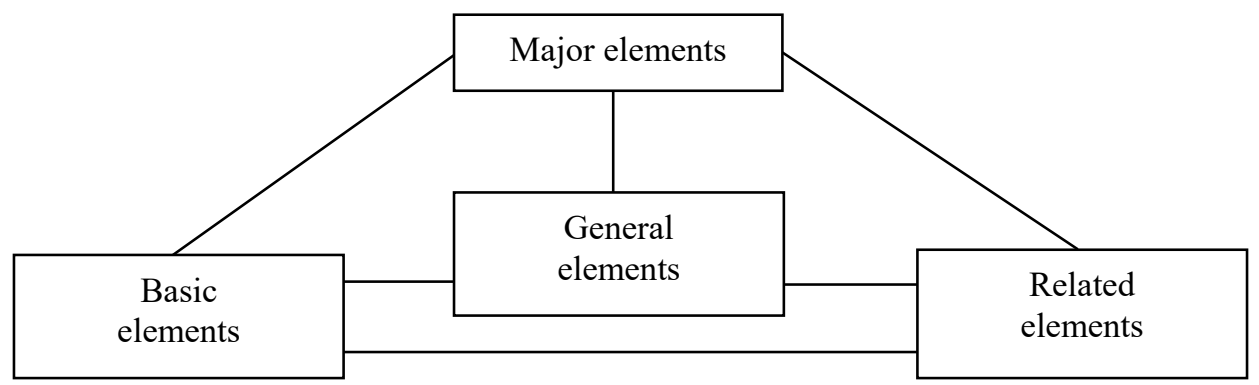

Fig. 1. The four element diagram 


\section{Analysis of structural elements of undergraduate universities}

According to the above technology related structural model view, discipline (specialty) is the main element of undergraduate universities, that is, the main carrier to realize the functions of undergraduate universities.

At the same time, there are basic elements to support the subject (Professional) elements, the essential factors, that is, the basic conditions required by the subject (Professional) elements to realize the function.

There are elements of other similar systems (Educational Systems) - general elements, the elements of each similar system (educational system) in the realization of functional processes, such as management elements, elements associated with the realization of the function of subject (Professional) elements - related elements, such as cultural elements.

Figure 2 shows the analysis of structural elements of undergraduate universities.

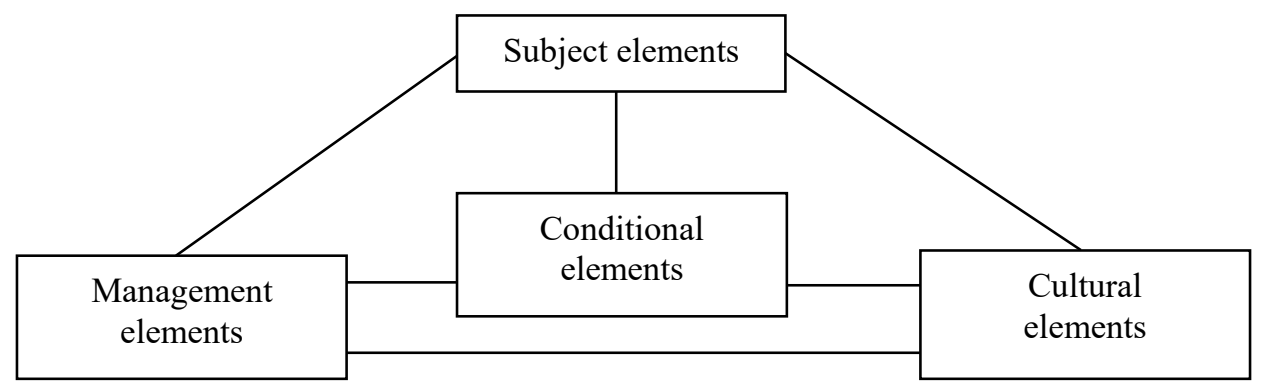

Fig. 2. Analysis of structural elements of undergraduate universities

\subsection{Subject (Major) elements}

In undergraduate universities, the carrier of talents training, scientific research and social service is the subject (specialty), that is, the subject (Major) in the undergraduate university is the carrier of cultivating advanced specialized talents and studying deep knowledge.

The first elements of the five elements, the second elements of the faculty, the equipment and the books in the third elements, that is, the subject (Professional) elements include the talents trained by the subject (Professional). Students, subject (Professional) team [this team is responsible for the mission of training talents, etc.], there are laboratory or research centers [the laboratory, according to the discipline (Professional) training talents and scientific research requirements, integrated equipment, books and materials, etc.), scientific research results [subject (Professional) publishing monographs, hair Tables, software programs, and tangible material achievements.

The four aspects of the subject (specialty) make the subject (specialty) become the core carrier of the undergraduate university. This carrier is specifically responsible for the functions of talent training and scientific research. It is the main symbol of the ability and level of the University.

\subsection{Conditional (basic) elements}

The elements of the condition mainly refer to infrastructure construction, library building construction, etc. These conditions have become the basic supporting conditions for Discipline (Professional) elements, which are mainly embodied in hardware content, namely, the hardware foundation of running schools.

In terms of the internal logic of running a school, the scale of the university is first to refer to the scale of the training of talents. Secondly, it refers to the scale of the teachers' team, the scale of the equipment and equipment, and the scale of the infrastructure, and so on.

From the point of view of applying for running a school, we must first have the scale of infrastructure, the size of teachers, and the scale of equipment and equipment, so as to apply for running schools. Only after having a school qualification can we have the scale of personnel training. Therefore, the construction of conditions (basic) elements is the main task in the initial stage of running schools. 


\subsection{Management (general) elements (including leading team and management team)}

Management elements (including leading group and management team) are the same as those mentioned above. As far as the subject (subject) element is concerned, management elements have become the universal requirements of external norms and constraints.

\subsection{Cultural (related) elements}

Cultural elements are the same as those mentioned above. Cultural elements are related factors for Discipline (main body) elements. The contents and forms of campus culture formed by different schools are different, so their emphasis is different.

For example, there are emphasis on theory, practice, and so on, and so on, these cultural factors are positive to the influence of people, but the emphasis on different aspects, so the cultural elements are related elements.

\section{Analysis on the development characteristics of structural elements of undergraduate universities in China}

The development of undergraduate university is subject to subject elements, basic factors, common elements of management, and cultural elements of relevance are the main contents of training the talents and scientific research, and their respective functions are played independently.

The factor of condition is the basis of the function of the discipline specialty, the management factor is the mechanism of the function of the discipline specialty, and the cultural element is the function environment of the subject. Equilibrium function means that conditions (basic) elements, management (general) elements and cultural (related) elements are in equilibrium when the function of a subject is played.

The various elements of the equilibrium state not only reach the requirements of running a school, but also make contributions to disciplines and specialties to make full use of their functions in the structure. The state that each element of the system plays a role according to the structure is a equilibrium state. The result of the structural function of the elements of the equilibrium state is the function of the school. The nature of this state is called equilibrium function.

According to the functions of undergraduate training, scientific research and social service, there are three levels of balanced function.

The first level is the balanced function of single function, that is, the equilibrium condition formed by discipline and professional personnel in terms of condition elements, management elements and cultural elements.

The second level is the balanced function of the dual function, that is, the equilibrium state of the subject specialty in training the talents, the factors of conditions, the management elements and the cultural elements in the scientific research.

The third level is the balanced function of the three function, that is, the equilibrium state of the factors, the factors of management and the cultural elements in the training of the subject, the scientific research and the social service.

Achieving different equilibrium functions marks the development of undergraduate universities to different functional stages.

\section{The Balanced functional development model of Chinese undergraduate universities oriented to structural elements}

The balanced function model of undergraduate university development means that after the coordinated development of scale, the structural elements of undergraduate universities play their respective roles in the structure. State and play the functions and processes of talent cultivation, scientific research and social service as a whole.

The main function of the undergraduate university is the training of talents. In order to realize the training function of talent, the undergraduate university is based on the basic elements of 
infrastructure and library house, and is based on the management elements of academic management and administrative management. It is related to the cultural elements such as academic atmosphere, study style and teaching style.

The above three elements are subject to the subject of students, teachers, equipment and academic achievements. As a result, the four kinds of structural elements represent the role of the undergraduate university to the society. The balanced function model of undergraduate university development refers to the development process of the function of each structural element around the discipline specialty to the society after the coordinated development of the scale is completed.

It is the first stage of the balanced functional model to provide the single function of talent training to the society; the second stages of the balanced functional model are the dual functions of providing talent training and scientific research to the society, and the three functions of providing talent training, scientific research and social service to the society are the third stages of the balanced functional model.

The balanced functional model of the three stages expresses the development of the University's function, which embodies the development of the balanced function of the university is the regular path of its connotation development, which indicates that the university has made more and more contributions to the society.

\section{Acknowledgement}

This research were financially supported by Heilongjiang Social Science Foundation (Grant No. 17SHD204).

\section{References}

[1] Z. P. Li, W. D. Wu: China Higher Education Research vol. 6 (2005), pp. 39

[2] Z. P. Li, W. D. Wu: China Higher Education Research vol. 7 (2006), pp. 56

[3] Z. P. Li, H. B. Zhang and et al: Heilongjiang Researches on Higher Education vol. 10 (2006), pp. 77

[4] Z. P. Li: Heilongjiang Researches on Higher Education vol. 3 (2005), pp. 22

[5] Z. P. Li: Education Exploration vol. 4 (2005), pp. 38

[6] Z. P. Li and et al: Journal of Harbin University vol. 10 (2005), pp. 64 